\title{
A smaller priming volume oxygenator for the Melrose-N.E.P. heart/lung machine
}

\author{
J C . A. RAISON
}

From the Thoracic Surgical Unit, King Edward VII Memorial Chest Hospital, nr. Warwick

One direction of the development of oxygenators for extracorporeal circulation has been an extension of their versatility by relating priming volumes to flows required. Bubble oxygenators, disc oxygenators of the Kay-Cross type, are easily altered in size, and Ross (1960) has developed two smaller versions of the Guy's Hospital model. In some small patients the extracorporeal circuit may be more than four times the patient's blood volume, and it would seem an important physiological criterion to reduce this disparity. In addition, it becomes increasingly essential to economize in blood donors and, as Melrose (1961) has said, 'the characteristic of priming volume will play a vital part in judging the merits of any heart / lung machine'. The widely used Melrose-N.E.P. oxygenator (Melrose and Aird, 1953 ; Cleland et al., 1958 ; Gerbode, Melrose, Norman, Osborn, Perkins, and Baer, 1958; Nixon, Grimshaw,
Catchpole, Snow, and Lawrance, 1960) is not so easily adapted, but a smaller version has been developed, achieving a significant saving of blood ; this can be used with only minor modifications to the standard apparatus.

\section{THE APPARATUS}

The oxygenator, which is a little less than half the standard length, has a narrower, deeper sectioned arterial well and, beyond this, three disc chambers of the usual size. The diameters are unchanged, and, although this limits design, it permits interchangeability and economy, and avoids major modifications to the standard base (Fig. 1). Two types of disc are used, the conventional crescentic type $\mathrm{C}$ discs, always, as in the standard version, in eccentric disc chambers assembled at $180^{\circ}$ to each other, and a new one. This new disc has a 3 in. $(7.5 \mathrm{~cm}$.)

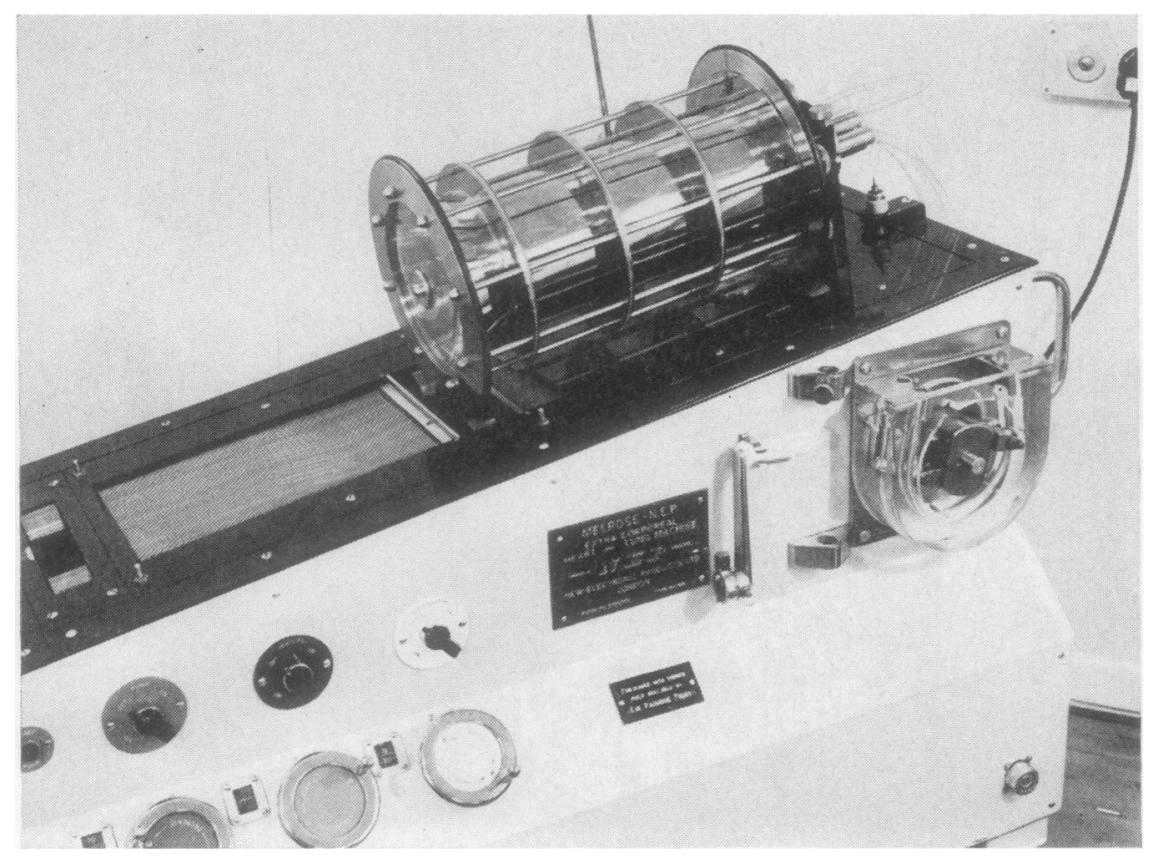

98
FIG. 1. The small oxygenator in position on the standard base. 


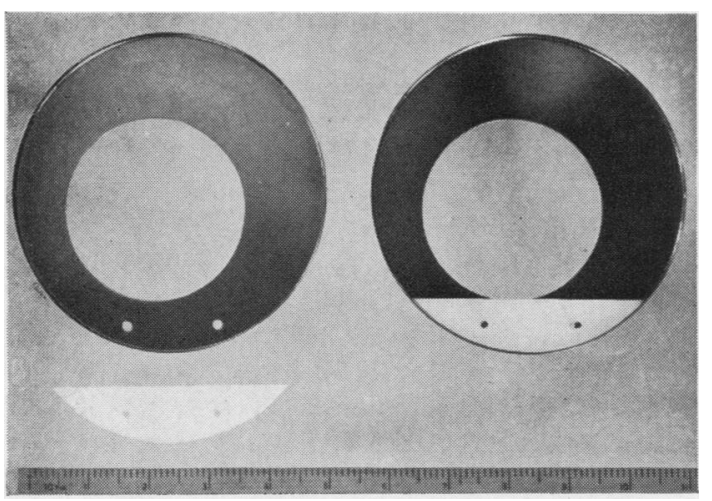

FIG. 2. Type $D$ disc and polypropylene $D$ showing method of assembly.

diameter hole punched $\frac{1}{4}$ in. off centre, and its surface area is modified by the insertion, between any two discs, of a 'spacer' shaped like the letter D, its circular edge being applied to the circumference of the disc chamber (Fig. 2). These Ds, 0.25 in. $(0.625 \mathrm{~cm}$.) thick, of autoclavable polypropylene, are retained by small stainless steel pins passing through holes punched in both discs and spacers. Both the alphabetical shape of the spacers and the previous sequence of disc types in the standard oxygenator justify these discs being called type $D$.

The assembly of these discs, which is initially a little complex, does not greatly increase the time needed. Such an arrangement is necessary to obtain optimum flow without turbulence. The oxygenator is usually made up from the arterial well, and it is convenient to consider that one is standing 'above' the arterial well, i.e., at the venous end. Concentric disc chambers, as for type A discs in the larger version, are always used. Five type $\mathrm{D}$ discs are inserted in the lowest chamber, each separated by a $D$ at $90^{\circ}$ in an anticlockwise direction from the eccentric displacement of the 'central' hole in the disc. The next group of five is similarly related, but the whole group is placed at $90^{\circ}$ anticlockwise to the previous group, and in the same manner each collection of five upwards to the venous end. Since the oxygenator rotates in a clockwise direction, these spacers in turn 'lift' a small volume of blood and permit its fall towards the arterial well. The eccentric bore provides a collecting space of varying depth beyond these Ds, and the whole effect is that blood falls to the lower end through a form of rotating helix, somewhat similar in pattern to that of the standard model (Nixon et al., 1960). The coils of the helix are, however, twice as close and the cross-sectional area is considerably reduced. The result is that at any time the volume of blood lifted for onward flow is only a quarter of that lifted in the standard model, and it is absorbed into a volume approximately three times its own size, whereas the standard model permits the forward flow of such large amounts that the provision of smoothing discs at the arterial end is necessary. Early experiments established that standard discs permitted too great a turbulence in the new small arterial well above $1,400 \mathrm{ml} . / \mathrm{min}$.

Two versions of the oxygenator are used. The intermediate form consists of the arterial well and three chambers containing 53 type $\mathrm{D}$ discs. Its maximum capacity is $2,300 \mathrm{ml}$./min., oxygenating venous blood of 45 to $55 \%$ saturation to 92 to $98 \%$. The smaller form consists of the same well, 20 type $\mathrm{D}$ discs, and 35 type $\mathrm{C}$ discs, the latter in eccentric chambers. Its maximum satisfactory output is $1,250 \mathrm{ml}$./min. for similar oxygenation. In each case maximum oxygenator rotation is $\mathbf{5 0}$ r.p.m.

PRIMING VOLUMES Operators, considering only the oxygenator or complete extracorporeal circuits of different patterns, find varying priming volumes for the standard machine. To provide some comparison, it has been found that standard circuits of similar pattern, with filter but no heat exchanger, need a minimum of $2,200 \mathrm{ml}$. for the lowest rates and up to $3,000 \mathrm{ml}$. for maximal flow. Both smaller versions can use $\frac{1}{4}$ in. $(0.625 \mathrm{~cm}$.) tubing in the pump and arterial line and $\frac{3}{8}$ in. $(0.9 \mathrm{~cm}$.) tubing for the venous side, and the maximum priming volumes are $1,250 \mathrm{ml}$. for the intermediate oxygenator-circuit and from 900 to $1,000 \mathrm{ml}$. for the smaller version. The machine is calibrated for each perfusion with normal saline, and the retained volume, which cannot be pumped out of the circuit, contributes to the priming volume. This reduces the demands for blood to $1,100 \mathrm{ml}$. and 800 to $900 \mathrm{ml}$. respectively. In addition, low molecular weight dextran can be substituted for part of this volume, provided that the calculated dilution of the patient's blood volume does not fall below $80 \%$ (Raison, 1962). The arterial well in fact contains the major part of the priming volume, $800 \mathrm{ml}$. when half full, so that the minimum priming volume for each version is about $150 \mathrm{ml}$. more than the smallest volume in the arterial well acceptable to the operator, usually equivalent to 30 to 40 seconds' flow. The time taken for blood to flow through the oxygenator varies, as in the standard model, from 15 to 25 seconds according to flow rate and oxygenator revolutions. The safety factor in the oxygenator is high, for at, say, $1,200 \mathrm{ml} . / \mathrm{min}$., using a circuit volume of $1,250 \mathrm{ml}$. and with the arterial well 
half full, any sudden obstruction to venous return will allow 40 seconds' perfusion before a dangerous level occurs in the well.

HAEMOLYSIS The characteristics are similar to those of the standard oxygenator. One litre of human blood recirculated without patient at 2,300 $\mathrm{ml}$./min. gave plasma haemoglobin level increases of 20 to $40 \mathrm{mg}$. $/ 100 \mathrm{ml}$. in 30 minutes, 40 to 55 mg. $/ 100 \mathrm{ml}$. in one hour. In clinical use the increases range from 30 to $40 \mathrm{mg} . / 100 \mathrm{ml}$./hour.

FOAMING It was anticipated that foaming would be the limiting factor in development of the oxygenator. The standard arterial well is an excellent debubbling chamber, and the new unit has a lesser capacity. Any further reduction would probably be impossible. Since the tube guide or 'trombone' can be supported entirely by the 'gate' at the venous end, the arterial window is intact, not pierced by a pivot, thus reducing foam-forming factors. This window, the well, both arterial and venous tube guide ends, and the inside of the upper end plate are treated with antifoam. With these provisions the bubbling which occurs at the highest flow rates is acceptable.

\section{MODIFICATION TO EXISTING MACHINE}

Certain parts of the oxygenators are interchangeable, but a new trombone is needed. The oxygenator rides on the upper part of the base, which requires a pair of additional rollers, easily fixed and not interfering with the function of the standard oxygenator. The inclination of the oxygenator must be increased slightly to $3 \frac{1}{2}$ in. $(8 \cdot 25 \mathrm{~cm}$.) from the horizontal at the bottom end of the oxygenator; this can be obtained in older models of the machine by depressing the arterial end of the swinging frame. Tubing of $\frac{1}{4}$ in. $(0.625 \mathrm{~cm}$.) diameter can be used in the standard pump, and $\frac{3}{8}$ in. $(0.9 \mathrm{~cm}$.) tubing in the venous occluder. The mirror and the light, whose intensity must be increased, need moving on a bracket. The two infrared lamps are not $\overrightarrow{\vec{\omega}}$ effective, and, although a third can be fitted above $+\overrightarrow{0}$ the small oxygenator, it is probably sufficient to $\frac{\mathrm{O}}{\mathrm{O}}$ rely on the heat exchanger usually included in $\overline{\mathrm{c}}$ any circuit.

Such a modification greatly enhances the value $\varrho$ of the Melrose heart/lung machine. Small volumes क of ordinarily stored ACD blood could safely be $\vec{\circ}$ used, with hypothermia, for emergencies such as surgically induced mitral insufficiency. In theory, $\omega$

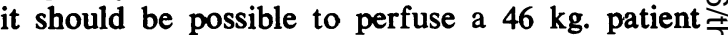
with $2,300 \mathrm{ml}$./min. previously cooled on partial $\times$ perfusion to $27^{\circ} \mathrm{C}$., using only $1,250 \mathrm{ml}$. low $\vec{\infty}$ molecular weight dextran. The machine is also $-\overrightarrow{0}$ suitable for regional cytotoxic perfusions using $\infty$ priming volumes of as little as $600 \mathrm{ml}$, and is probably cheaper than disposable bubble $\rightarrow$ oxygenators when frequently used.

This work was begun in the Department of Experimental Surgery at the Postgraduate Medical School, $\mathscr{\mathscr { C }}$ Hammersmith, in association with Dr. D. S. Melrose, $\omega$ while I was holding a part-time appointment there and was fully developed in the Wellcome Surgicalo Research Laboratories, Queen Elizabeth Hospital, Birmingham, by kind permission of Professor F. A. R. Stammers, with funds made available by the Research $\stackrel{0}{2}$

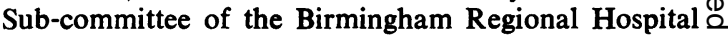
Board. My thanks are also due to Mr. N. J. Shah $\overrightarrow{\vec{B}}$ and Dr. G. Dabbah for their surgical help. The oxygenator is manufactured by New Electronic Products, Ltd.

\section{REFERENCES}

Cleland, W. P., Beard, A. J. W., Bentall, H. H., Bishop, M. B., C. Braimbridge, M. V., Bromley, L. L., Goodwin, J. F., Hollman, A., Kerr, W. F., Lloyd-Jones, E. B., Melrose, D. S., and Telivuo, J. (1958). Brit. med. J., 2, 1369.

Gerbode, F., Melrose, D. S., Norman, A., Osborn, J. J., Perkins, H. A., and Baer, D. M. (1958). Lancet, 2, 284.

Melrose, D. S. (1961). Ann. Rev. Med., 12, 67. - and Aird, I. (1953). Brit. med. J., 2, 57.

Nixon, P. G. F. Grimshaw, V. A., Catchpole, L. A, Snow, H. M. and Lawrance, K. (1960). Thorax, 15, 193.

Raison, J. C. A. (1962). Jbid., 17, 338

Ross, D. N. (1960). Lancet, 2, 1064. 